\title{
Hypertension Unusual Cause
}

\author{
Ana Belén Hernández Cascales ${ }^{1}$, Alicia Hernández Torres ${ }^{2}$, María Ángeles Ibáñez Gil ${ }^{3}$, \\ Pedro Pujante Alarcón ${ }^{1}$, Alfonso López Ruiz ${ }^{4}$, María Dolores Hellín Gil ${ }^{1}$, Juan Mayor Barrancos ${ }^{5}$ \\ ${ }^{1}$ Endocrinology and Nutrition Service, Hospital University Virgen de la Arrixaca, Murcia, Spain; ${ }^{2}$ Infectious Internal Medicine, Hos- \\ pital University Virgen de la Arrixaca, Murcia, Spain; ${ }^{3}$ Health Center Mariano Yago, Murcia, Spain; ${ }^{4}$ University of Granada, Grana- \\ da, Spain; ${ }^{5}$ Roman Alberca Psychiatric Hospital, El Palmar, Spain. \\ Email: ${ }^{*}$ alfonsolopezruizmail@gmail.com
}

Received September $8^{\text {th }}, 2013$; revised October $14^{\text {th }}, 2013$; accepted October $28^{\text {th }}, 2013$

Copyright (c) 2014 Ana Belén Hernández Cascales et al. This is an open access article distributed under the Creative Commons Attribution License, which permits unrestricted use, distribution, and reproduction in any medium, provided the original work is properly cited. In accordance of the Creative Commons Attribution License all Copyrights @ 2014 are reserved for SCIRP and the owner of the intellectual property Ana Belén Hernández Cascales et al. All Copyright @ 2014 are guarded by law and by SCIRP as a guardian.

\section{ABSTRACT}

We expose a case of a woman with hypertension and hypokalemia. The differential diagnosis should include primary hyperaldosteronism, diuretics or lazantes intake, secondary hyperaldosteronism. In this patient, additional tests performed show no cause of hormonal disruption and the whole picture is due to a high intake of licorice. Glycyrrhetinic acid, the active component of licorice, inhibits renal IIbeta-hydroxisteroid dehydrogenase. This allows cortisol to stimulate mineralocorticoid receptors. Licorice ingestion should be considered in the differential diagnosis of hypertension with hypokalemia.

\section{KEYWORDS}

\section{Licorice; Glycyrrhizic Acid; Glycyrrhizinic Acid; Induced Hypertension; Hypokalemia}

\section{Introduction}

Due to the high prevalence of hypertension in the general population, we should always take into account the possibility of one form of secondary hypertension, especially when signs give us a suspicion. These suspect data of secondary hypertension include spontaneous or induced hypokalemia by a diuretic drug, a drug refractory hypertension and no family history of hypertension [1].

First of all, we should think about the probability of primary hyperaldosteronism, because of its high prevalence. Also we must include in the differential diagnosis the other causes of hypertension and hypokalemia; among them, because of its frequency, we have to consider the administration of diuretics and renovascular disease. We also include the "aldosterone-non dependent hipermineralcorticism” and secondary hyperaldosteronism.

\section{Case Report}

We present the case of a woman of 57 years, ex-smoker, with Type 1 Diabetes Mellitus 8 years of evolution,

\footnotetext{
${ }^{*}$ Corresponding author.
}

treated with continuous insulin infusion system. She had no family history of hypertension or other relevant medical history or chronic treatment. Her metabolic control was good with HbA1c $6.5 \%$ to $7.5 \%$. There were no known complications of diabetes. The total daily insulin requirements were $0.5 \mathrm{IU}$ per $\mathrm{kg}$ of body weight.

The patient begins with a hypertension clinic with systolic blood pressure values (SBP) of $180-170 \mathrm{~mm}$ $\mathrm{Hg}$ and diastolic blood pressure (DBP) of 95 - 105 $\mathrm{mmHg}$ along with hypokalemia $(2.2 \mathrm{mmol} / \mathrm{L})$ and normal renal function (creatinine $0.85 \mathrm{mg} / \mathrm{dl}$, creatinine clearance $86 \mathrm{ml} / \mathrm{min}$ ). The hypertension does not respond to style 3-drug combination antihypertensive high dose (Atenolol $100 \mathrm{mg}$ daily, Amlodipine $10 \mathrm{mg}$ daily, and Valsartan $320 \mathrm{mg}$ daily), and low levels of potassium persisted despite an oral supplement. First initial laboratory abnormalities (hypokalemia) focus the search of the cause of the hypertension in a mineralocorticoid excess.

Physical examination: Weight $64 \mathrm{~kg}$, height $161 \mathrm{~cm}$, BMI 24.6, blood pressure 154/97, HR 68 bpm. Head and Neck: normocolored and normohydrated; No carotid bruits; No yugular engorgement; No goiter or lympha- 
denopathy. Cardiac auscultation: rhythmic murmurs, normal lung sound in both lungs. No megali abdominal masses or abdominal murmurs. Lower limbs with symmetrical palpable pulses, without edema.

Results of additional tests performed were:

- Analytical Overview: glucose $103 \mathrm{mg} / \mathrm{dl}$, creatinine $0.85 \mathrm{mg} / \mathrm{dl}$, urea $38 \mathrm{mg} / \mathrm{dl}$, sodium $143 \mathrm{mEq} / \mathrm{ml}$, potassium $2.0 \mathrm{mEq} / \mathrm{ml}$, hematocrit 38\%, 7.3\% HbA1c, venous blood gases analysis shows alkalosis metabolic (pH 7.42, bicarbonate $34 \mathrm{mmol} / \mathrm{l}, \mathrm{pCO}_{2} 53 \mathrm{mmHg}$ ).

- Certain hormones: TSH $3.0 \mathrm{mIU} / \mathrm{L}$, Aldosterone plasmatic $4 \mathrm{ng} / \mathrm{dl}$, ratio of plasma aldosterone/renin 18, plasma cortisol $22.2 \mathrm{mg} / \mathrm{dl}$, ACTH basal 28 (normal $<50$ ), normal 11Deoxicortisol, 17-alpha-OH-progesterone normal, urinary free cortisol (24-hour urine) 35 mcg (normal $<90$ ), urine catecholamines in 24 hours normal.

- Abdominal CT: Both adrenal glands of normal morphologic features.

- ECG: sinus rhythm at 68 beats per minute, T wave flattening, ST segment changes are not or QT.

- The patient denied bowel habit disturbances and vomiting. Directed in history, the patient denied surreptitious use of laxatives, diuretics or other drugs. Only highlighted the high overuse licorice candy in the last 6 months, in relation to smoking cessation.

After stopping the intake of licorice, were normalized blood pressure values without specifying any drug, and potassium level sreturned to normal.

\section{Discussion}

The differential diagnosis of hypertension and hypokalemia can be systematically approached by first measuring urine potassium to rule outskin and/or gastrointestinal losses. Measurement of 24-h urinary potassium excretion establishes excessive loss most definitely, but this procedure was not done in this patient [2]. Urinary potassium wasting can be caused by loop diuretics or thiazides. These diuretics low blood pressure, but may not be sufficient to normalize in refractory hypertension. Our patient denied the use of diuretics.

There are also genetic conditions that physiologically mimic the use of diuretics. Bartter syndrome is an autosomal recessive channelopathy channel $\mathrm{Na}-\mathrm{K}-2 \mathrm{Cl}$ in the thick ascending limb of Henle's loop. Patients with this condition present in childhood with metabolic alkalosis and increased urinary potassium, sodium, and chloride [2].

Gitelman's syndrome is an autosomal recessive channelopathy $\mathrm{Na}-\mathrm{Cl}$ transporter in the distal collecting duct that can mimic hyperaldosteronism and may occur in the future. Patients with these genetic defects usually have low normal blood pressure [2].

Among hypertensive patients with hypokalemia and metabolic alkalosis, Cushing syndrome, mineralocorti- coid excess or primary or secondary hyperaldosteronism can cause hypokalemia. This patient, however, had normal aldosterone and had no physical signs consistent with Cushing's syndrome [2].

Pseudo hyperaldosteronism presented in the low renin and aldosterone may be due to genetic or acquired etiologies. Liddle's syndrome (autosomal dominant channelopathy transporter $\mathrm{Na} / \mathrm{K}$ in the renal collecting tubules) occurs at a younger age [2].

Genetic deficiency of 11- $\beta$ hydroxysteroid dehydrogenase type 2 ( $\beta$-HSD2 11) leads to apparent mineralocorticoid excess and sometimes occurs in adulthood. $11 \beta$-HSD2 is normally abundant in the kidney tubules and selectively converts cortisol to cortisone. In deficiency states, the unmetabolized cortisol rapidly binds to receptors of aldosterone and it results in mineralocorticoid effects such as sodium retention and potassium loss, leading to hypertension and hypokalemia [3] (12), and, as a consequence, metabolic alkalosis following hypokalemia. 11 $\beta$-HSD2 deficiency is rare and may be evaluated by sequencing ADN. Congenital adrenal hyperplasia presents with low aldosterone, but the late onset form usually does not cause significant loss of renal electrolyte. Ectopic ACTH syndrome or a deoxycorticosterone-secreting adenoma adrenal could also occur with low renin and aldosterone [2].

Licorice-Induced Hypertension and Hypokalemia: Consuming large amounts of black licorice candy has been associated with hypertension and hypokalemia. Licorice root contains glycyrrhizin and biologically active (glycyrrhizic acid, glycyrrhizinic acid). Glycyrrhizin is a triterpenoid saponin glycoside used as an intense sweetener in confectionery and for their supposed beneficial effects against inflammation, viruses, ulcers and gastrointestinal upset. However, glycyrrhizin inhibits the metabolism of cortisol and can lead to acute and chronic cases of severe hypertension and hypokalemia [2]

Glycyrrhizin Mechanism: Glycyrrhetinic acid, the active component of licorice, inhibits renal IIbeta-hydroxysteroid dehydrogenase. This allows cortisol to stimulate mineralocorticoid receptors, which can lead to hypertension and hypokalemia [2] (Figure 1).

The European Union recommends $100 \mathrm{mg} /$ day limit for ingestion of glycyrrhizin (about the amount found in 60 - 70 licorice g) [4]. However, the susceptibility with glycyrrhizin is influenced by baseline health status and genetic polymorphisms [5].

\section{Conclusion}

This case illustrates the licorice-containing supplements as a possible cause of hypertension and significant hypokalemia. In the context of hypertension and hypokalemia, the differential diagnosis of primary aldostero- 


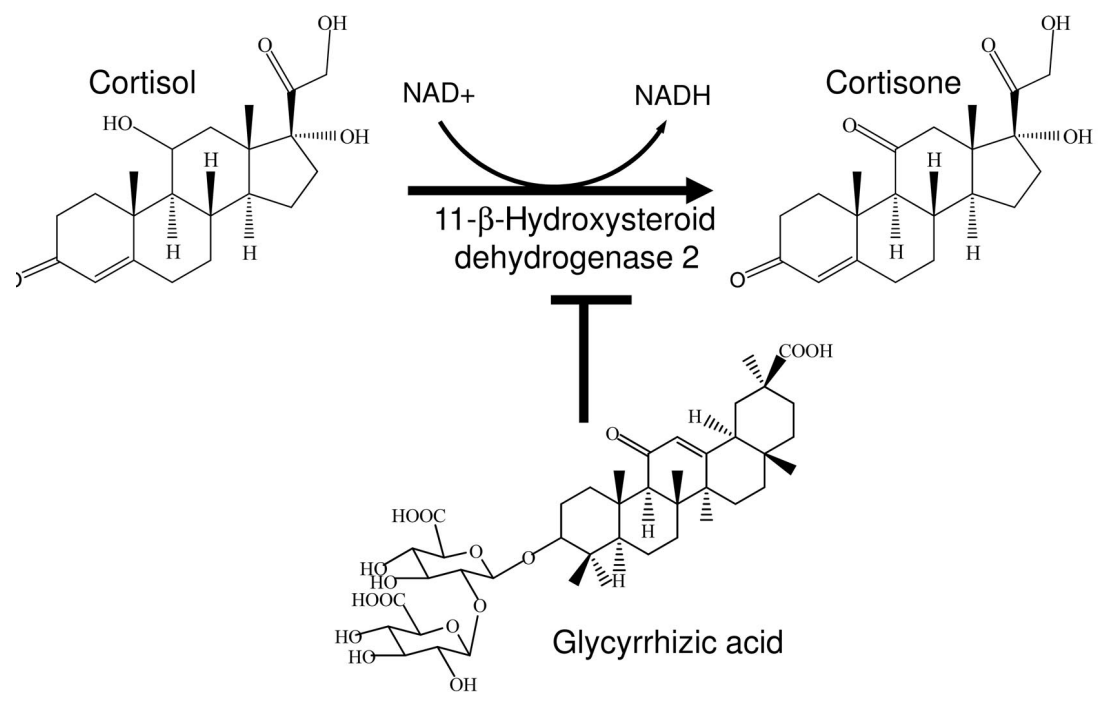

Figure 1. Glycyrrhizin mechanism.

nism is very important. The most common causes are exogenous, diuretics and laxatives, or endogenous secondary hyperaldosteronism as Bartter's symdrome and renovascular disease. Despite the rarity of this case, licoriceingestion should be taken into account as a cause of hypertension.

\section{REFERENCES}

[1] J. W. Funder, R. M. Carey, C. Fardella, C. E. GomezSanchez, F. Mantero, M. Stowasser, W. F. Young Jr. and V. M. Montori, "Case Detection, Diagnosis, and Treatment of Patients with Primary Aldosteronism: An Endocrine Society Clinical Practice Guideline,” Journal of Clinical Endocrinology \& Metabolism, Vol. 93, No. 9, 2008, pp. 3266-3281. http://dx.doi.org/10.1210/jc.2008-0104

[2] S. C. Murphy, S. Agger and P. M. Rainey, "Too Much of a Good Thing: A Woman with Hypertension and Hypokalemia,” Clinical Chemistry, Vol. 55, No. 12, 2009, pp. 2093-2096.

http://dx.doi.org/10.1373/clinchem.2009.127506

[3] P. C. White, T. Mune and A. K. Agarwal, "11-Beta-hydroxysteroid Dehydrogenase and the Syndrome of Apparent Mineralocorticoid Excess," Endocrine Reviews, Vol. 18, No. 1, 1997, pp. 135-136.

http://dx.doi.org/10.1210/er.18.1.135

[4] Scientific Committee on Food, "Opinion of the Scientific Committee on Food on Glycyrrhizinic Acid and Its Ammonium Salt," European Commission Heath and Consumer Protection Directorate General, Brussels, 2012.

[5] H. A. Sigurjonsdottir, K. Manhem, M. Axelson and S. Wallerstedt, "Subjects with Essential Hypertension Are More Sensitive to the Inhibition of 11 Beta-HSD by Liquorice," Journal of Human Hypertension, Vol. 17, 2003, pp. 125-131. http://dx.doi.org/10.1038/sj.jhh.1001504 